\title{
Coagulase-negative Staphylococcus, catheter-related, bloodstream infections and their association with acute phase markers of inflammation in the intensive care unit: An observational study
}

\author{
Oleksa Rewa MD ${ }^{1}$, John Muscedere MD FRCPC ${ }^{1,2,3}$, Steve Reynolds MD FRCPC ${ }^{4,5}$, \\ Xuran Jiang $\mathrm{MSc}^{3}$, Daren K Heyland MD FRCPC MSc ${ }^{1,2,3}$
}

O Rewa, J Muscedere, S Reynolds, X Jiang, DK Heyland. Coagulase-negativeStaphylococcus, catheter-related, bloodstream infections and their association with acute phase markers of inflammation in the intensive care unit: An observational study. Can J Infect Dis Med Microbiol 2012;23(4):204-208.

OBJECTIVE: To examine the relationship between the isolation of coagulase-negative Staphylococcus in blood cultures and acute phase markers of inflammation.

METHODS: The present study was a prospective observational analysis conducted at three medical/surgical intensive care units (ICUs) involving adult patients with an expected ICU stay of more than $24 \mathrm{~h}$ duration.

RESULTS: Of the 598 patients enrolled, 573 developed suspected bloodstream infection and $434(72.6 \%)$ had blood cultures sent $24 \mathrm{~h}$ after ICU admission; 142 were excluded due to positive cultures from other sites. Of the remaining 292 patients, 31 (10.7\%) grew coagulasenegative Staphylococcus, 59 (20.2\%) grew known pathogenic organisms and $202(69.2 \%)$ did not grow any organisms in their blood cultures. Twenty-five patients without suspicion of infection served as the control group. Interleukin (IL)-6, procalcitonin (PCT) and C-reactive protein (CRP) levels were highest among the known pathogen group (IL-6 271.8 U/L, PCT 4.6 U/L and CRP $164 \mathrm{mg} / \mathrm{L}$ ), were similar between the coagulase-negative Staphylococcus and negative culture groups (IL-6 67.0 U/L versus 61.4 U/L [P=1.00]; PCT $1.0 \mathrm{U} / \mathrm{L}$ versus $0.9 \mathrm{U} / \mathrm{L}[\mathrm{P}=0.80]$; and CRP $110 \mathrm{mg} / \mathrm{L}$ versus $103 \mathrm{mg} / \mathrm{L}$ $[\mathrm{P}=0.75]$ ), and were lowest in the control group (IL-6 $31.0 \mathrm{U} / \mathrm{L}, \mathrm{PCT}$ $0.2 \mathrm{U} / \mathrm{L}$ and CRP $41.0 \mathrm{mg} / \mathrm{L}$ ). In the coagulase-negative Staphylococcus group, patients who died by day 28 had increased inflammatory biomarker levels compared with survivors, although the differences were not statistically significant.

CONCLUSIONS: Coagulase-negative Staphylococcus isolated from blood cultures were associated with lower levels of inflammation compared with bloodstream infections due to known pathogens and were comparable with levels in patients with negative cultures.

\begin{abstract}
Les infections du sang par le staphylocoque à coagulase négative, les infections du sang liées au cathéter et leur association avec les marqueurs d'inflammation en phase aiguë à l'unité de soins intensifs : une étude d'observation
\end{abstract}

\begin{abstract}
OBJECTIF : Examiner la relation entre l'isolement de staphylocoque à coagulase négative dans les hémocultures et les marqueurs d'inflammation en phase aiguë.

MÉTHODOLOGIE : Étude d'observation prospective

LIEU : Trois unités de soins intensifs (USI) médicaux et chirurgicaux

PATIENTS : Tous les patients dont le séjour prévu à l'USI pour adultes dépassait 24 heures

RÉSULTATS : Sur les 598 patients participants, 573 ont présenté une présomption d'infection du sang, et une hémoculture a été envoyée en laboratoire 24 heures après l'admission à l'USI de 434 (72,6 \%) d'entre eux; 142 ont été exclus en raison de cultures positives d'autres foyers. Sur les 292 patients restants, $31(10,7 \%)$ ont développé un staphylocoque à coagulase négative, $59(20,2 \%)$, des organismes pathogènes connus et $202(69,2 \%)$ ne présentaient aucun organisme dans le sang. Vingt-cinq patients sans présomption d'infection ont servi de groupe témoin. Les taux d'interleukine (IL)-6, de procalcitonine (PCT) et de protéine C réactive (CRP) étaient les plus élevés dans le groupe infecté par des pathogènes connus (IL-6 271,8 U/L, PCT 4,6 U/L et CRP 164 mg/L), étaient similaires dans les groupes de staphylocoque à coagulase négative et aux cultures négatives (IL-6 67,0 U/L par rapport à 61,4 U/L [P=1,00]; PCT 1,0 U/L par rapport à $0,9 \mathrm{U} / \mathrm{L}[\mathrm{P}=0,80]$ et $\mathrm{CRP} 110 \mathrm{mg} / \mathrm{L}$ par rapport à $103 \mathrm{mg} / \mathrm{L}$ $[\mathrm{P}=0,75]$ ) et étaient les plus faibles dans le groupe témoin (IL-6 31,0 U/L, PCT 0,2 U/L et CRP 41,0 mg/L). Dans le groupe ayant un staphylocoque à coagulase négative, les patients qui étaient décédés le $28^{\mathrm{e}}$ jour présentaient des taux de biomarqueurs inflammatoires plus élevés que les survivants, même si les différences n'étaient pas statistiquement significatives.

CONCLUSIONS : Le staphylocoque à coagulase négative isolé dans les hémocultures s'associait à des taux plus faibles d'inflammation que les infections du sang causées par des pathogènes connus et était comparable aux taux observés chez les patients dont les cultures étaient négatives.
\end{abstract}

Key Words: Catheter-related bloodstream infection; Coagulase-negative Staphylococcus; C-reactive protein; Interleukin-6; Procalcitonin

Catheter-related, bloodstream infections (CRBSIs) are a major source of morbidity and mortality in the intensive care unit (ICU). Coagulase-negative Staphylococcus (CoNS) is the most commonly encountered organism in CRBSIs, causing between $11 \%$ and $45 \%$ of infections with an incidence of 15.8 per 10,000 hospital admissions $(1,2)$, at an associated cost of US $\$ 33,000$ to US $\$ 71,000$ per episode (3). The incidence of CoNS CRBSIs is increasing with the increased use of implanted devices, such as central venous catheters and temporary dialysis catheters (4), which are especially common in the ICU, secondary to the frequent requirement for one or more of these catheters, and the repeated requirements for access to these devices due to the severity of underlying patient disease (5).

${ }^{1}$ Department of Medicine; ${ }^{2}$ Critical Care Program, Queen's University; ${ }^{3}$ Clinical Evaluation Research Unit, Kingston General Hospital, Kingston, Ontario; ${ }^{4}$ Critical Care Program, University of British Columbia; ${ }^{5}$ Department of Critical Care, Royal Columbian Hospital, Vancouver,

British Columbia

Correspondence: Dr Daren K Heyland, Kingston General Hospital, Angada 4, 76 Stuart Street, Kingston, Ontario K7L 2V7.

Telephone 613-549-6666 ext 4847, fax 613-548-2428, e-mail dkh2@queensu.ca 
When blood cultures performed for suspected infection are positive for CoNS, it is often difficult to determine whether the presence of this organism in the blood is a pathogen or a contaminant. There have been several strategies proposed to enhance the diagnosis of CoNS CRBSIs (6), but these methods remain imperfect and often involve the removal of the catheter in question for diagnosis. Most commonly, the diagnosis of CoNS CRBSI remains a clinical diagnosis and one of exclusion, where no other potential source of infection or infectious organism is identified.

Systemic inflammation in the ICU, as manifested by systemic inflammatory response syndrome (SIRS), is very common (7). Distinguishing between SIRS caused by infection and SIRS secondary to other causes is very challenging clinically, and there is an increasing amount of literature evaluating the utility of biomarkers for this indication (8). These biomarkers include interleukin (IL)- 6 and the acute phase markers of inflammation procalcitonin (PCT) and C-reactive protein (CRP), among others. These new biomarkers have been used in enhancing the diagnosis of infection and predicting patient outcome (9-11) but have not yet been applied to predicting patient outcome and guiding clinical decision making regarding CRBSIs caused by CoNS.

The purpose of the present study was to determine whether patients with blood cultures positive for CoNS had associated elevations of inflammatory biomarkers. We hypothesized that CoNS-positive blood cultures generally do not cause elevations in acute phase markers of inflammation, as seen in bacteremias with known pathogens, but that increased levels of acute phase markers of inflammation within CoNSpositive blood culture populations may be predictive of poorer clinical outcomes. If our hypothesis is correct, then acute phase markers of inflammation may be useful in guiding management and predicting clinical outcomes.

\section{METHODS}

A prospective, multicentre, observational study in three general medical/ surgical tertiary care ICUs for the primary purpose of evaluating a novel diagnostic marker for sepsis, was conducted (12). A secondary analysis examining the relationship between bloodstream infections and inflammatory mediators is also described. All patients admitted to the ICU and expected to stay more than $24 \mathrm{~h}$ were included. Individuals admitted for routine cardiac monitoring (ie, elective surgery), overdoses and pediatric patients $(<18$ years of age), were excluded. Because the overall goal was to compare the levels of inflammatory markers associated with isolated CoNS in blood cultures with other known pathogen levels in the blood, patients with infections at other sites were excluded. Blood cultures were ordered as per clinical suspicion of infection and at the discretion of the clinical team. Two researchers reviewed patient charts independently to ensure appropriate group allocation. Study patients were divided into the following four groups according to the organisms grown in the blood cultures: patients who grew known pathogens in their blood (eg, Acinectobacter species, Aeromonas species, Burkholderia cepacia, Citrobacter species, Escherichia coli, Enterobacter species, Enterococcus species, Haemophilus influenzae, Klebsiella species, Moraxella catarrhalis, Morganella species, Neisseria meningitidis, Pasteurella species, Proteus species, Pseudomonas aeruginosa, Serratia species, Staphylococcus aureus, Stenotrophomonas maltophilia, beta-hemolytic Streptococcus and Streptococcus pneumonae); patients who grew CoNS in their blood with no other organisms in the blood or at other sites within $72 \mathrm{~h}$ of their culture draw date; patients who did not grow any microorganisms in their blood cultures or at any other site within $72 \mathrm{~h}$ of their culture draw date; and patients without any suspicion of infection, as indicated by the fact that they never had any blood cultures drawn or antibiotics prescribed. These patients served as the control group. This selective grouping of patients was established in an attempt to provide a 'pure' group of patients admitted to the ICU to enable answering of the study question. For patients with drawn-blood cultures, the levels of acute phase markers of inflammation were obtained within $24 \mathrm{~h}$ of the blood culture being drawn.
To determine the levels of acute phase markers of inflammation for the control group, blood was drawn on day 3 of ICU admission. To be considered noninfected, day 3 of ICU admission was chosen to allow sufficient time in the ICU without suspicion of infection.

\section{Clinical management}

Because the present study was observational in nature, the clinical team was responsible for making all management decisions. Decisions pertaining to culturing blood and initiating antibiotic therapy were left to the discretion of the clinical teams.

\section{Clinical data collection}

Baseline demographics, medical history and reasons for ICU admission were obtained from patients or their charts. Necessary variables were recorded to calculate Acute Physiology and Chronic Health Evaluation II (APACHE II) (13), on admission, and Sequential Organ Failure Assessment (SOFA) scores (14) daily until day 28, death or discharge from the ICU.

\section{Laboratory tests}

Blood samples were collected in the morning following enrollment and each subsequent day until discharge from the ICU, death or a maximum of 10 days. Plasma was analyzed for inflammatory markers using the following assays: CRP (high-sensitivity cardiac C-reactive protein reagent used in conjunction with the UniCel DxC 600/800 system, Beckman Coulter Inc, USA), procalcitonin (B.R.A.H.M.S PCT LIA, Thermo Fisher Scientific, Germany); IL-6 (ELISA kit, Cat BMS-213, Bender Med Systems Inc, USA). Blood cultures were drawn throughout the ICU admission as indicated based on a clinical suspicion of infection.

\section{Outcome measures}

The clinical outcomes for the present study included 28-day mortality, ICU-free days and ventilator-free days in the first 28 days, and maximum and delta SOFA scores. The delta SOFA score was calculated by subtracting the maximal SOFA score from the baseline SOFA score (14).

\section{Statistical analysis}

Patient characteristics, clinical outcomes and biomarkers within $\pm 24 \mathrm{~h}$ of the index date were compared among four patient groups with different organisms grown in blood cultures. Categorical variables were described as counts and percentages and were compared using the $\chi^{2}$ test. Normally distributed variables were described as means \pm SDs and compared using the ANOVA test, whereas other continuous variables were described as medians with quartiles, and differences were tested using the Kruskal-Wallis test (15). Box-and-whisker plots were used to depict the inflammatory biomarker levels among the four patient groups and between 28-day survivors and nonsurvivors.

\section{RESULTS}

A total of 598 patients were enrolled in the present study. Twentyeight patients had no antibiotics prescribed and no cultures sent from $48 \mathrm{~h}$ before to 14 days after ICU admission. Three of these patients were excluded (one patient had a diagnosed infection the week before and two patients died within $72 \mathrm{~h}$ of ICU admission), and the remaining 25 patients served as the control group. Of the remaining 570 patients, $434(72.6 \%)$ had at least one blood culture drawn $48 \mathrm{~h}$ after ICU admission. Of these, 142 were excluded because they had another site with a positive culture (ie, sputum) $(n=130)$ or because only the line tip was positive $(n=12)$ with no associated positive blood culture. Of the remaining 292 patients, 31 (10.6\%) had blood cultures positive only for CoNS, 59 (20.2\%) were positive for other previously described pathogens and 202 (69.2\%) had negative blood cultures (Figure 1).

Baseline patient characteristics (Table 1) were similar among the CoNS, known pathogen-positive and culture-negative groups, but differed significantly from the control group. The control-group patients were younger and had lower APACHE II and SOFA scores. Moreover, 


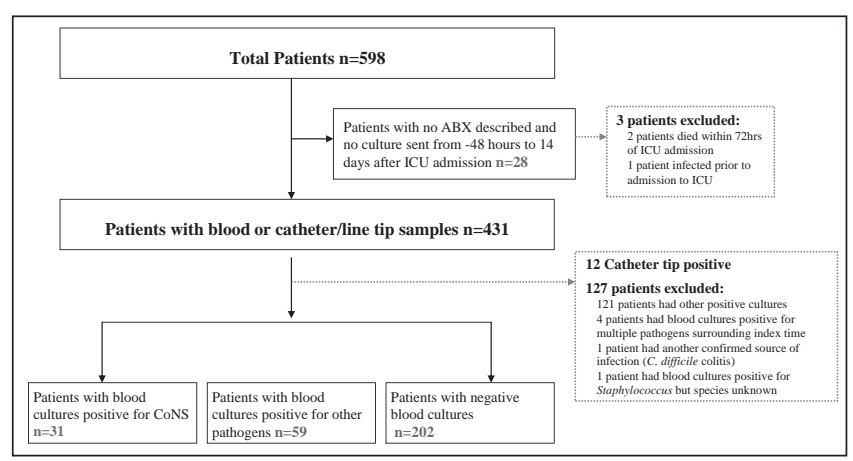

Figure 1) Flowchart depicting the patient breakdown and allocation for the study population. Patients with catheter tip-positive cultures were excluded from the final analysis. ABX Antibiotics; CoNS Coagulase-negative Staphylococcus; ICU Intensive care unit

the primary admission diagnosis differed significantly among groups with a predominance of sepsis in the known pathogen-positive group.

Levels of IL-6, PCT and CRP were highest in the group with blood cultures positive for known pathogens, lower in the CoNS and negativeculture groups, and lowest in the control group $(\mathrm{P}<0.05$, Table 2$)$. Acute phase markers of inflammation levels were most similar between the CoNS and negative culture groups (IL-6 $67.0 \mathrm{IU} / \mathrm{L}$ versus 61.4 IU/L [P=1.00]; PCT 1.0 IU/L versus $0.9 \mathrm{IU} / \mathrm{L}[\mathrm{P}=0.80]$; and CRP $110 \mathrm{mg} / \mathrm{L}$ versus $103 \mathrm{mg} / \mathrm{L}[\mathrm{P}=0.75])$, and values were lowest in the control group for each of IL-6, PCT and CRP (31.0 IU/L, 0.2 IU/L and $41.0 \mathrm{mg} / \mathrm{L}$, respectively) (Table 2 ).

The overall mortality rate in the study population was $25.6 \%$ at 28 days. The mortality rate was highest among the known pathogen group and lowest in the control group $(37.3 \%$ versus $0 \% ; \mathrm{P}=0.005)$. The mortality rate was similar between the CoNS and culture-negative groups at 28 days (22.6\% versus $25.7 \% ; \mathrm{P}=0.71$ ) (Table 3 ).

In the CoNS group, seven (22.6\%) patients died. There were no statistically significant differences in inflammatory cytokines levels at $24 \mathrm{~h}$ between survivors and nonsurvivors (Table 4). However, in absolute

\section{TABLE 1}

\section{Baseline patient characteristics}

\begin{tabular}{|c|c|c|c|c|c|}
\hline & Other pathogens $(n=59)$ & CoNS $(n=31)$ & Negative culture $(n=202)$ & Control $(n=25)$ & $\mathrm{P}^{*}$ \\
\hline Age, years & $63.4 \pm 15.1$ & $63.5 \pm 15.4$ & $60.4 \pm 15.5$ & $51.6 \pm 19.7$ & 0.01 \\
\hline Sex, male, n (\%) & $30(50.8)$ & $17(54.8)$ & $116(57.4)$ & $12(48.0)$ & 0.71 \\
\hline APACHE II score & $25.6 \pm 7.7$ & $23.5 \pm 7.9$ & $22.4 \pm 7.0$ & $12.3 \pm 6.4$ & $<0.001$ \\
\hline Baseline SOFA score & $6.3 \pm 2.8$ & $5.3 \pm 3.0$ & $4.9 \pm 2.8$ & $1.3 \pm 1.6$ & $<0.001$ \\
\hline Comorbidities, n & $3.0 \pm 1.4$ & $3.3 \pm 1.4$ & $3.0 \pm 1.3$ & $3.1 \pm 1.4$ & 0.79 \\
\hline Admission, n (\%) & & & & & 0.27 \\
\hline Medical & $50(84.7)$ & $25(80.6)$ & $147(72.8)$ & $18(72.0)$ & \\
\hline Surgical & $9(15.3)$ & $6(19.4)$ & $54(26.7)$ & $7(28.0)$ & \\
\hline Primary admission diagnosis, $\mathrm{n}(\%)$ & & & & & $<0.001$ \\
\hline Cardiovascular/vascular & $6(10.2)$ & $4(12.9)$ & $19(9.4)$ & $3(12.0)$ & \\
\hline Respiratory & $17(28.8)$ & $12(38.7)$ & $72(35.6)$ & $2(8.0)$ & \\
\hline Gastrointestinal & $8(13.6)$ & $4(12.9)$ & $32(15.8)$ & $3(12.0)$ & \\
\hline Neurological & $2(3.4)$ & $3(9.7)$ & $12(5.9)$ & $2(8.0)$ & \\
\hline Sepsis & $14(23.7)$ & $1(3.2)$ & $12(5.9)$ & $0(0.0)$ & \\
\hline Trauma & $5(8.5)$ & $3(9.7)$ & $16(7.9)$ & $4(16.0)$ & \\
\hline Metabolic & $4(6.8)$ & $1(3.2)$ & $12(5.9)$ & $7(28.0)$ & \\
\hline Postoperative conditions & $2(3.4)$ & $1(3.2)$ & $17(8.4)$ & $4(16.0)$ & \\
\hline Renal & $0(0.0)$ & $2(6.5)$ & $4(2.0)$ & $0(0.0)$ & \\
\hline Orthopedic & $1(1.7)$ & $0(0.0)$ & $5(2.5)$ & $0(0.0)$ & \\
\hline Heart rate, beats/min & $120.1 \pm 22.5$ & $110.5 \pm 23.7$ & $110.1 \pm 21.4$ & $102.7 \pm 19.6$ & 0.01 \\
\hline Temperature, ${ }^{\circ} \mathrm{C}$ & $38.3 \pm 1.4$ & $37.7 \pm 1.5$ & $38.2 \pm 1.3$ & $37.9 \pm 0.5$ & 0.24 \\
\hline Respiratory rate, breaths/min & $28.5 \pm 9.4$ & $29.0 \pm 12.9$ & $26.0 \pm 8.3$ & $28.1 \pm 6.7$ & 0.20 \\
\hline White blood cell count, $\times 10^{9} / \mathrm{L}$ & $13.7 \pm 10.2$ & $12.4 \pm 6.7$ & $13.3 \pm 6.3$ & $8.7 \pm 2.7$ & 0.10 \\
\hline
\end{tabular}

Data presented as mean $\pm S D$ unless otherwise indicated. *P represents comparisons between control group, other pathogens, coagulase-negative Staphylococcus (CoNS) and negative culture groups. Statistically significant P values are highlighted in bold. APACHE II Acute Physiology and Chronic Health Evaluation II; SOFA Sequential Organ Failure Assessment 
TABLE 2

Inflammatory biomarker levels according to group

\begin{tabular}{|c|c|c|c|c|c|}
\hline & Other pathogen $(n=59)$ & CoNS $(n=31)$ & Negative culture $(n=202)$ & Control $(n=25)$ & $\mathrm{P}^{*}$ \\
\hline Procalcitonin, U/L (n) & $4.6(24)$ & $1.0(13)$ & $0.9(113)$ & $0.2(18)$ & $<0.05$ \\
\hline Interleukin-6, U/L (n) & $271.8(24)$ & $67.0(13)$ & $61.4(113)$ & $31.0(17)$ & $<0.02$ \\
\hline
\end{tabular}

Data presented as median values of inflammatory biomakers drawn within $24 \mathrm{~h}$ of the index date, unless otherwise indicated. ${ }^{*} P$ values are representative of comparisons made between other pathogens and coagulase-negative Staphylococcus (CoNS), negative culture and control groups

TABLE 3

Clinical outcomes according to group

\begin{tabular}{|c|c|c|c|c|c|}
\hline & Other pathogens $(n=59)$ & CoNS $(n=31)$ & Negative culture $(n=202)$ & Control $(n=25)$ & $\mathbf{P}$ \\
\hline Maximum SOFA & $11.1 \pm 3.8$ & $8.3 \pm 3.6$ & $8.8 \pm 4.0$ & $3.2 \pm 2.0$ & $0.001^{\star \dagger}$ \\
\hline Days on mechanical ventilation & $8.0 \pm 8.4$ & $5.6 \pm 4.5$ & $5.9 \pm 5.8$ & $0.6 \pm 0.8$ & $<0.001^{*}$ \\
\hline Mortality at day $28, \mathrm{n}(\%)$ & $22(37.3)$ & $7(22.6)$ & $52(25.7)$ & $0(0.0)$ & $0.005^{*}$ \\
\hline
\end{tabular}

Data presented as mean \pm SD unless otherwise indicated. ${ }^{\star} P$ between control group and other pathogen, coagulase-negative Staphylococcus (CoNS) and negative culture groups; ${ }^{\dagger} P$ between other pathogen and CoNS group. SOFA Sequential Organ Failure Assessment

exotoxin-producing strains may be associated with higher levels of acute phase markers of inflammation and increased mortality. However, exotoxin levels were not quantified in collected blood, and additional studies examining the presence of exotoxin in the blood of patients infected with $S$ epidermidis and other CoNS need to be performed to investigate this hypothesis.

Another possible explanation for CoNS not being associated with increased levels of inflammatory biomarkers may stem from CoNS being a contaminant in the blood cultures. If this were the case, patients would not truly be infected and it may be inferred that inflammatory biomarker level would not be elevated. The study population may itself include two different subpopulations: one that had true blood culture positivity with CoNS and another in which CoNS was as a contaminant. Contamination of blood cultures by CoNS is most likely to occur at the time of collection due to breaks in asceptic culture collection technique. Biomarkers may be useful to differentiate between these two populations. Currently, there are no validated or well-studied methods to accomplish this, and the number of blood cultures that return positive for CoNS is what is most commonly used at present to provide this differentiation. Unfortunately, we did not quantify the percentage of blood cultures that were positive for CoNS, so it is not possible to solidify this conclusion. Additional work quantifying and adjudicating true CoNS CRBSIs versus CoNS contamination is necessary to determine whether biomarkers may be used to aid in this differentiation.

Absolute bacterial load may have contributed to the levels of inflammation biomarkers and patient outcomes. According to this hypothesis, higher organism load in the blood may cause increased inflammation and lead to poorer patient outcome. The present study was not structured to answer this question, and more work will need to be performed to test this hypothesis. Finally, CoNS bacteremia may not necessarily be the cause of inflammation but may be an epiphenomena in patients who have systemic inflammation caused by SIRS. If this hypothesis was correct, then treatment of the underlying cause of SIRS would be all that is required, rather than treatment for the CoNS.

While the mortality rate of patients with blood cultures positive for CoNS was similar to those with negative cultures, there was a wide range of inflammatory profiles in these patients. Recently, there has been much work focused on uncovering novel markers of inflammation. The most important and promising of these in bacterial infections include IL-6, CRP and PCT $(21,22)$. IL-6 has been previously demonstrated to be closely related to the severity of the physiological response to infection and systemic inflammation, and PCT has been shown to be related to the systemic inflammatory response, especially when associated with bacterial infections (23). CRP is an acute phase protein that is released by the liver as a consequence of inflammation but is less specific than both IL-6 and PCT for inflammation secondary

\section{TABLE 4}

Coagulase-negative Staphylococcus biomarkers and outcomes

\begin{tabular}{lccc}
\hline & \multicolumn{2}{c}{ Patients } & \\
\cline { 2 - 3 } & $\begin{array}{c}\text { Deceased by } \\
\text { day 28 }(\mathbf{n}=\mathbf{7})\end{array}$ & $\begin{array}{c}\text { Alive at } \\
\text { day 28 (n=24) }\end{array}$ & \multicolumn{1}{c}{$\mathbf{P}$} \\
\hline Procalcitonin, U/L (n) & $1.5(3)$ & $0.6(11)$ & 0.31 \\
C-reactive protein, mg/L (n) & $136.5(6)$ & $103.0(17)$ & 0.42 \\
Interleukin-6, U/L (n) & $102.7(3)$ & $65.4(11)$ & 0.70 \\
\hline
\end{tabular}

Data presented as median values unless otherwise indicated

to infection (24-26). Previous studies have demonstrated that while IL-6, PCT and CRP levels are all elevated in septic patients, IL-6 and PCT levels correlate with SOFA scores and may be predictive of clinical outcome $(10,25)$. In the present study, when compared with survivors, patients with blood cultures positive for CoNS and who died by 28 days had elevated levels of IL-6, PCT and CRP within $24 \mathrm{~h}$ of their positive blood cultures (Figure 3 ). These findings were not statistically significant because of the small sample size, but the differences were clinically important. Statistically significant differences, however, may have emerged between these two groups had a larger sample size been available; this would be necessary to suffciently power an investigation of this finding.

A limitation of the present study was the small sample size. Our measurements of IL-6, PCT and CRP levels showed great variability, and given the small sample size and large variability, the present study was underpowered to show statistically significant differences in acute phase markers of inflammation. Ultimately, these observations are hypothesis generating and require additional studies to examine the role of CoNS in the systemically inflamed patient. An additional limitation was that we could not determine overall bacterial burden. Unfortunately, while we collected culture results, we did not keep track of how many sets of blood cultures were sent to the laboratory and, thus, we cannot comment on the proportion of positive cultures in each patient. This prevents us from attempting to establish bacterial load and likely contaminants versus true bacteremias, and from making any concrete conclusions regarding the CoNS-bloodstream load and its relationship to systemic inflammation. Additional work will need to be performed to investigate these theories.

\section{CONCLUSION}

The levels of acute phase markers of inflammation are elevated in critically ill patients. CoNS isolated in blood cultures are associated with lower levels of inflammation compared with bloodstream infections due to known pathogens and are comparable with patients who 
have negative cultures. In the subset of patients with CoNS-positive blood cultures, higher levels of IL-6, PCT and CRP were associated with increased mortality. Additional studies are needed to determine whether inflammatory biomarker levels may be used to guide antibiotic therapy in patients with CoNS.

DISCLOSURES: The authors have no financial disclosures or conflicts of interest to declare.

\section{REFERENCES}

1. Chung H, Cartwright M, Bortz D, Jackson T, Younger J. Dynamical system analysis of Staphylococcus epidermidis bloodstream infection. Shock 2008;30:518-26.

2. Richards M, Thursky K, Buising K. Epidemiology, prevalence, and sites of infections in intensive care units. Semin Respir Crit Care Med 2003;24:3-22.

3. Maki D, Crnich C. Line sepsis in the ICU: Prevention, diagnosis, and management. Semin Respir Crit Care Med 2003;24:23-36.

4. Boyce JM. Epidemiology and prevention of nosocomial infections. In: The Staphylococcus in Human Disease. Crossley K, Archer G, eds. New York: Churchill Livingston, 1996:309-30.

5. Spencer RC. Epidemiology of infections in ICUs. Intensive Care Med 1994;20(Suppl 4):S2-S6.

6. Safdar N, Fine J, Maki D. Meta-analysis: Methods for diagnosing intravascular device-related bloodstream infection. Ann Intern Med 2005; 142:451-66.

7. Bone RC, Balk RA, Cerra FB, et al. Definitions for sepsis and organ failure and guidelines for the use of innovative therapies in sepsis. Chest 1992;101:1644-55.

8. Philipp S, Mirjam C, Beat M. Biomarkers to improve diagnostic and prognostic accuracy in systemic infections. Curr Opin Crit Care 2007;13:578-85.

9. Friedland J, Porter J, Daryanani S, et al. Plasma proinflammatory cytokine concentrations, Acute Physiology and Chronic Health Evaluation (APACHE) III scores and survival in patients in an intensive care unit. Crit Care Med 1996;24:1775-81.

10. Oberhoff M, Vogelsang H, Russwurm S, Hartung T, Reinhart K. Outcome prediction by traditional and new markers of inflammation in patients with sepsis. Clin Chem Lab Med 1999;37:336-68.

11. Gabay C, Kushner I. Acute phase proteins and other systemic responses to inflammation. N Engl J Med 1999;340:6 448-54.

12. Heyland DK, Govert J, Garrard C. Waveform abnormalities of APTT in critically ill hospitalized patients: The WATTCH study. Crit Care Med 2006;34:A100.
13. Knaus WA, Draper EA, Wagner DP, Zimmerman JE. APACHE II: A severity of diseases classification system. Crit Care Med 1985;13:818-29.

14. Moreno R, Vincent JL, Matos R, et al. The use of maximum SOFA score to quantify organ dysfunction/failure in intensive care. Results of a prospective, multicenter, study. Intensive Care Med 1999;25:686-96.

15. Neter J, Wasserman W, Whitmore GA. Applied Statistics, 4th edn. Boston: Allyn and Bacon, 1993.

16. Marin ME, de la Rosa MC, Cornejo I. Enterotoxigenicity of Staphylococcus strains isolated from Spanish dry-cured hams. Appl Environ Microbiol 1992;58:1067-9.

17. Bialecka A, Mak M, Biedron R, Bobek M, Kasprowicz A, Marcinkiewicz J. Different pro-inflammatory and immunogenic potentials of Propionibacterium acnes and Staphylococcus epidermidis: Implication for chronic inflammatory acne. Arch Immunol Ther Exp 2005;53:79-85.

18. Huebner J, Goldmann DA. Coagulase negative Staphylococcus: Role as pathogens. Annu Rev Med 1999;50:223-36.

19. Otto M. Staphylococcus epidermidis - the 'accidental' pathogen. Nature 2009;8:555-67.

20. Bautista L, Gaya P, Medina M, Nunez M. A quantitative study of enterotoxin production by sheep milk staphylococci. Appl Environ Microbiol 1988;54:566-9.

21. Gabay C, Kushner I. Acute-phase proteins and other systemic responses to inflammation. N Engl J Med 1999;340:448-54.

22. Oberhoffer M, Vogelsang H, Russwurm S, Hartung T, Reinhart K. Outcome prediction by traditional and new markers of inflammation in patients with sepsis. Clin Chem Lab Med 1999;37:363-8.

23. Ugarte H, Silva E, Mercan D, De Mendonca A, Vincent JL. Procalcitonin used as a marker of infection in the intensive care unit. Crit Care Med 1999;27:498-504.

24. Meisner M, Tschaikowsky K, Palmaers T, Schimdt J. Comparison of procalcitonin (PCT) and C-reactive protein (CRP) plasma concentrations at different SOFA scores during the course of sepsis and MODS. Crit Care 1999;3:45-50.

25. Selberg O, Hecker H, Martin M, Klos A, Bautsch W, Kohl J. Discrimination of sepsis and systemic inflammatory response syndrome by determination of circulating plasma concentrations of procalcitonin, protein complement $3 \mathrm{a}$, and interleukin-6. Crit Care Med 2000;28:2793-8.

26. Schuetz P, Mueller B, Trampuz A. Serum procalcitonin for discrimination of blood contamination from bloodstream infection due to coagulase-negative Staphylococci. Infection 2007;35:352-5. 


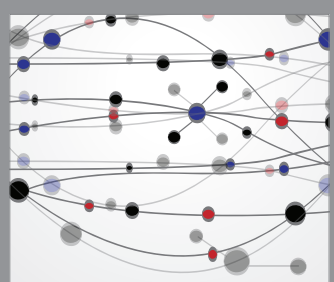

The Scientific World Journal
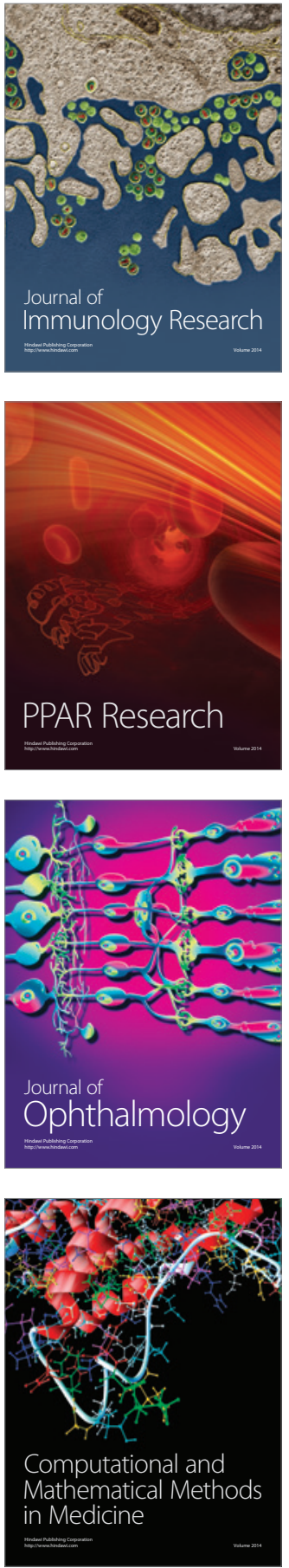

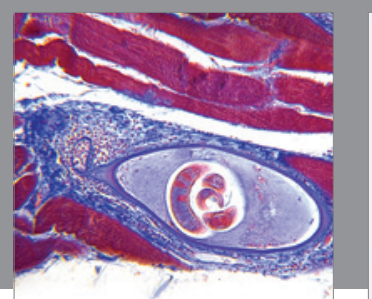

Gastroenterology Research and Practice

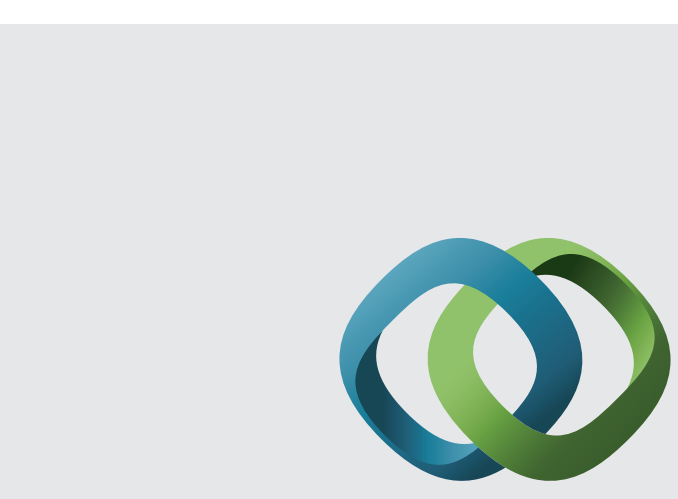

\section{Hindawi}

Submit your manuscripts at

http://www.hindawi.com
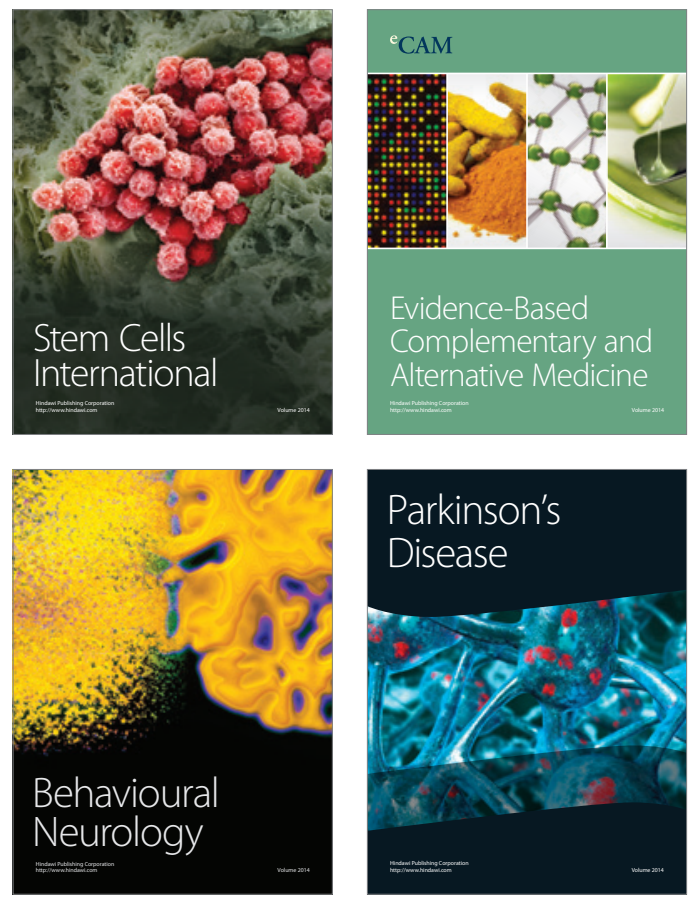
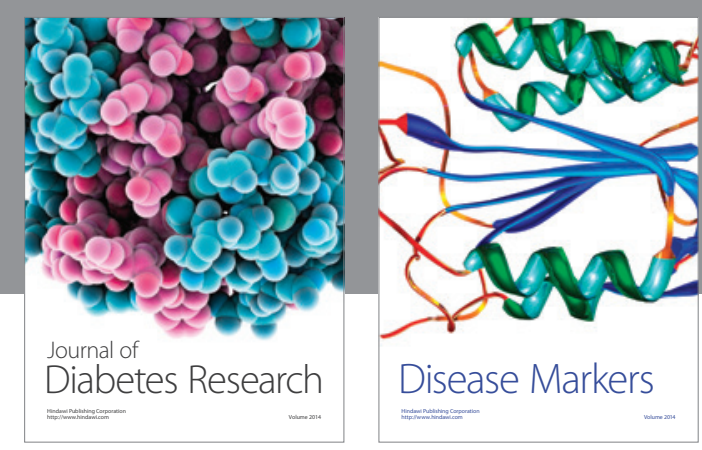

Disease Markers
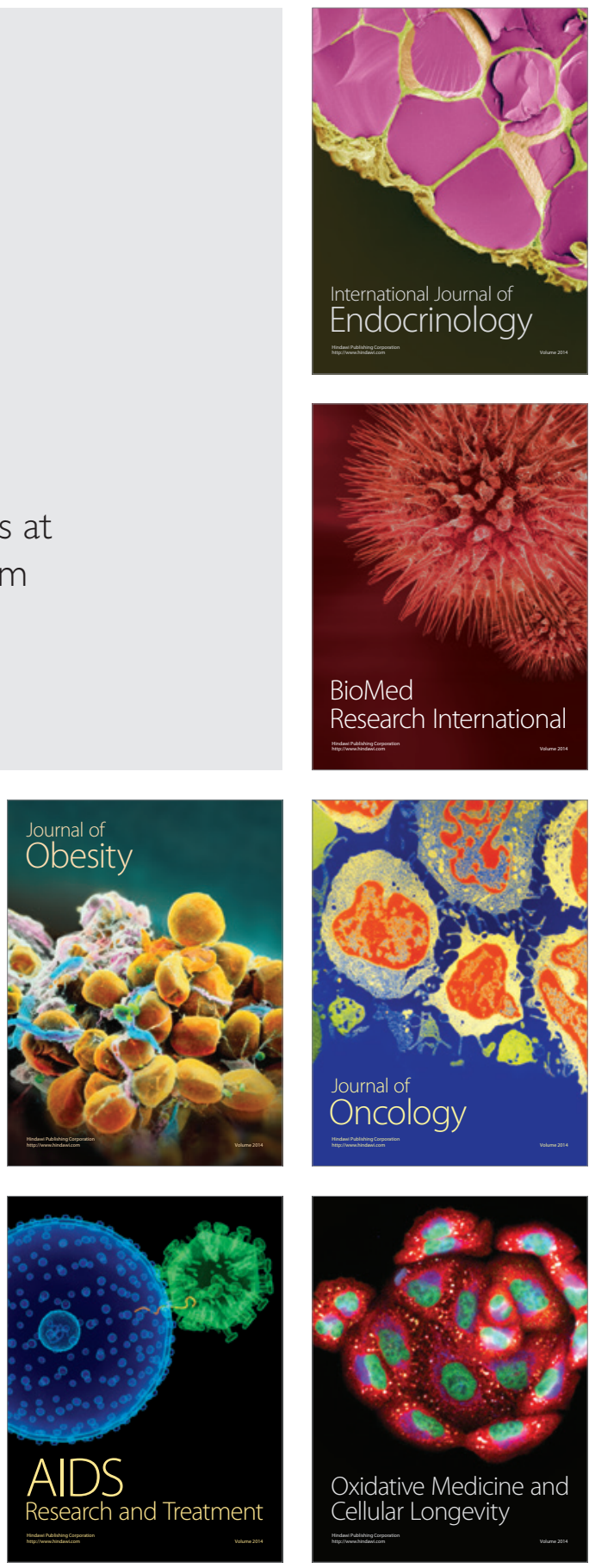